\title{
Evaluation of Inoculation Techniques for Fusarium Ear Rot and Fumonisin Contamination of Corn
}

\author{
M. J. Clements and C. E. Kleinschmidt, Department of Crop Sciences, University of Illinois, Urbana 61801; \\ C. M. Maragos, USDA-ARS Mycotoxin Research Unit, Peoria, IL 61604; and J. K. Pataky and D. G. White, De- \\ partment of Crop Sciences, University of Illinois, Urbana
}

\begin{abstract}
Clements, M. J., Kleinschmidt, C. E., Maragos, C. M., Pataky, J. K., and White, D. G. 2003. Evaluation of inoculation techniques for Fusarium ear rot and fumonisin contamination of corn. Plant Dis. 87:147-153.

Fumonisins have been associated with potentially serious toxicoses of animals and humans. Prior to initiating a corn (Zea mays) breeding program for resistance to these mycotoxins, an efficient inoculation technique must be developed. Four inoculation techniques were evaluated on 14 commercial corn hybrids in Urbana, IL in 1999 and 2000. The techniques were: injection of inoculum through the ear husk leaves at R2 (blister); silks sprayed with inoculum at R2 and covered with a shoot bag until harvest; silks sprayed with inoculum at R2, covered with a shoot bag, reinoculated 1 week thereafter, and covered with a shoot bag until harvest; and insertion of six Fusarium-colonized toothpicks into the silk channel at R2. Only injection of inoculum through the husk leaves significantly increased the concentration of fumonisin in grain and severity of Fusarium ear rot compared with a control. This technique effectively differentiated hybrids previously identified as resistant or susceptible to Fusarium ear rot. The rank order of hybrids inoculated with this technique did not significantly change in the 2 years of this study. This technique is suitable for efficiently evaluating a large number of corn genotypes for resistance to Fusarium ear rot and fumonisin concentration.
\end{abstract}

Additional keywords: Fusarium moniliforme, F. proliferatum, F. verticillioides, maize

A group of mycotoxins known as the fumonisins has been associated with Fusarium ear rot of corn (Zea mays L.) since 1988 (23). These homologous compounds are secondary metabolites of several Fusarium Link species, including $F$. verticillioides (Sacc.) Nirenberg (syn. $=$ F. moniliforme J. Sheld.) and $F$. proliferatum (Matsushima) Nirenberg-two species which are found worldwide in temperate regions where corn is produced (47). Fusarium ear rot is favored by hot, dry conditions at flowering coupled with high humidity (79). High fumonisin concentrations in grain have been associated with dry weather at or just before pollination (70); however, specific conditions that favor fumonisin production are not fully understood. Fumonisins have been experimentally shown to be the causal agent of equine leukoencephalomalacia (ELEM; $38,44,63,64,80)$, porcine pulmonary edema $(14,29,30,41,56,64)$, cardiac failure in

Corresponding author: D. G. White

E-mail: d-white@uiuc.edu

Research support was provided by CFAR grant IDACF01I-14-3 and NRI grant AG2001-3520110060.

Accepted for publication 10 September 2002.

Publication no. D-2002-1119-03R

(C) 2003 The American Phytopathological Society baboons (41), atherogenic effects in vervet monkeys (21), hepatic cancer in mice and rats $(22,24,55)$, neural tube defects in mice (25), and renal cancer in rats (55). The American Association of Veterinary Laboratory Diagnosticians recommended that feed for horses and swine contain fumonisins at less than 5 and $10 \mu \mathrm{g} / \mathrm{g}$, respectively (45). The United States Food and Drug Administration (FDA) has issued a "Guidance for Industry" for fumonisins in feed of several animal species (9).

Although a cause and effect relationship has not been demonstrated clearly, evidence exists of potentially serious human health problems associated with consumption of corn products contaminated with fumonisin. Fumonisin has been associated with human esophageal cancer in China $(10,12)$, South Africa $(60,76)$, and northern Italy (16). Fumonisin $B_{1}$, the most common and most toxic fumonisin identified in corn grain $(52,77)$, and its hydrolysis products also were present in tortillas consumed by a population in south Texas which experienced an increased incidence of neural tube birth defects (73).

Current FDA Guidance levels for fumonisins between 2 and $4 \mu \mathrm{g} / \mathrm{g}$ have been suggested for various dry milled corn products (8) pending a more permanent long-term risk management policy. Numerous studies indicate that grain from much of the Midwest corn crop has been contaminated at fumonisin concentrations between 0 and $5 \mu \mathrm{g} / \mathrm{g}$, and that concentrations above $5 \mu \mathrm{g} / \mathrm{g}$ are common in some years $(1,47,51,68,82)$. Thus, a substantial portion of the corn crop in the United States could be affected when fumonisin accumulation in grain is favored.

Fumonisin in corn-based human food is not common in the United States, although contamination has been reported in corn meal $(7,37,57,61,74,75)$, corn grits $(75)$, muffin mix $(7,57)$, corn bread mix $(7)$, tortilla chips $(7,37)$, tortillas $(73)$, and beer (35) purchased at various locations. The public is generally unaware of fumonisin, and federal guidelines do not yet regulate its presence in food or feed; therefore, there is little information available on breeding for resistance to fumonisin concentration in corn grain. Potential problems resulting from regulation of fumonisins may be averted by a proactive strategy aimed at reducing the incidence and concentration of fumonisin in corn grain prior to processing. Resistance will provide producers and consumers with environmentally sound, economical control of fumonisins. Prior to initiating a breeding program for resistance, efficient techniques for inoculating ears with Fusarium spp. and for detecting mycotoxins must be developed.

An efficient inoculation technique must be developed to differentiate hybrids identified as resistant or susceptible under natural infection. Compared with natural infection, inoculation increases disease severity and decreases variability within and among treatments. High levels of resistance identified from inoculated trials will enable breeders to develop hybrids that are useful to producers during normal growing seasons and during growing seasons when disease development is favored. Effective inoculation and subsequent evaluation of corn germ plasm also should lead to a reduction of fumonisin in grain of commercial corn hybrids and minimize economic disruptions when fumonisin production is favored.

Several inoculation techniques for Fusarium ear rot have been described $(5,19,27,31-33,36,46,50,65,67,69)$; however, only two of these studies measured the concentration of fumonisin in grain $(5,67)$, and only one (5) measured fumonisin in grain from multiple genotypes from different commercial corn companies. In general, severe Fusarium ear rot was 
associated with techniques that delivered inoculum directly to corn kernels at an early stage of ear development.

The concentration of fumonisin and severity of Fusarium ear rot are somewhat correlated; however, fumonisin has been reported at levels of concern in asymptomatically infected grain $(4,12,47,53,54,60)$. Therefore, inoculation techniques that are effective for ear rot may not be effective for the assessment of fumonisin in grain. The objective of this study was to identify an inoculation technique that is suitable for the efficient evaluation of a large number of corn genotypes for resistance to Fusarium ear rot and fumonisin in grain from the Central United States.

\section{MATERIALS AND METHODS}

Seed of 14 commercial corn hybrids obtained from Monsanto Company (St. Louis) and Pioneer Hi-Bred International, Inc. (Des Moines, IA) were planted at the University of Illinois Crop Sciences Research and Education Center, Urbana, on 1 May 1999 and 28 April 2000. The hybrids had been described as resistant or susceptible to Fusarium ear rot based on information available from Pioneer Hi-Bred International, Inc. or by previous research (5). The experimental design was a randomized complete block arranged as a split plot with four replicates. Inoculation techniques were applied to main plots and hybrids were planted in subplots. Experimental units were single rows consisting of 20 to 24 plants. Rows were $5.3 \mathrm{~m}$ long (plus a fallow alley of $\pm 0.5 \mathrm{~m}$ ) and spaced $0.8 \mathrm{~m}$ apart. The treatment design was analyzed as a 5-by-14 factorial with five inoculation treatments and 14 hybrids.

A control and four inoculation techniques designed to promote the development of Fusarium ear rot and fumonisin in grain were evaluated. The techniques were (i) injection of $5 \mathrm{ml}$ of a spore suspension through the husk leaves into the side of the primary ear when plants reached the R2 (blister) growth stage (injection); (ii) silks of the primary ear sprayed with $5 \mathrm{ml}$ of a spore suspension at R2 and covered with a waxed paper shoot bag (model \#217; Lawson Bags, Northfield, IL) until harvest (spray/cover); (iii) silks of the primary ear sprayed with $5 \mathrm{ml}$ of a spore suspension at $\mathrm{R} 2$, covered with a waxed paper shoot bag, reinoculated 1 week thereafter, and covered with a shoot bag until harvest (spray/cover/spray); and (iv) insertion of six Fusarium-colonized toothpicks into the silk channel of the primary ear at R2 (toothpicks).

Inoculum was prepared from two isolates of $F$. verticillioides (numbers 42 and $150)$ and three isolates of $F$. proliferatum (numbers 19, 37-2, and 310) that produced severe Fusarium ear rot and a high concentration of fumonisin in grain when isolates were injected into corn ears in a concurrent study (13). Inoculum also was prepared from one isolate of $F$. verticillioides (number 152) that did not produce fumonisin in the same study. All six isolates are maintained at the University of Illinois. Isolates were grown on potato dextrose agar (Becton Dickinson and Company, Sparks, MD) at approximately $25^{\circ} \mathrm{C}$ under $12 \mathrm{~h}$ of diurnal fluorescent light.

Inoculum for spray and injection inoculations was prepared by blending an equal number of cultures of the six isolates with deionized water. The resulting propagule suspension was strained through two layers of cheesecloth, further diluted with water to a concentration of $10^{6}$ conidia/ml as determined with a hemacytometer, and amended with Tween 20 surfactant (polyoxyethylene 20-sorbitan monolaurate; Fisher Biotech, Fairlawn, NJ) at 0.2 $\mathrm{ml} /$ liter. Spray inoculations were applied with backpack sprayers (model 425; Solo Inc., Newport News, VA) equipped with cone nozzles. Injection inoculations were applied with Solo backpack sprayers equipped with an injection device consisting of a Tee-Jet brand meter jet (model 23623-31; Spraying Systems Co., Wheaton, IL) fitted with a $0.64-\mathrm{cm}$ Tee-Jet outlet adapter (model 4676) and a 2.4-by-0.2-cm hollow stainless steel needle (University of Illinois Civil and Environmental Engineering Machine Shop, 1137 Newmark Lab, Urbana). Inoculum for toothpick inoculations was prepared by initially autoclaving approximately 1,800 toothpicks in 4 liters of deionized water. All water was removed and the process was repeated. Water was removed again before the toothpicks were separated into groups of approximately 300 , sealed into 2-liter Fernbach flasks containing $250 \mathrm{ml}$ of potato dextrose broth (Becton Dickinson and Company), autoclaved at $121^{\circ} \mathrm{C}$ for $20 \mathrm{~min}$, and allowed to cool to room temperature. Each flask was inoculated with one of the six Fusarium isolates chosen for this study, and the cultures were allowed to incubate for 9 days at approximately $25^{\circ} \mathrm{C}$ under $12 \mathrm{~h}$ of diurnal fluorescent light. Individual cultures were kept separate until the time of inoculation to insure that ears were treated with a mixture of all six isolates. One toothpick from each of the six cultures was inserted into the silk channel of the primary ear at the R2 growth stage.

All primary ears in an experimental unit were harvested at approximately $18 \%$ grain moisture, rated for severity of Fusarium ear rot as the percentage of the ear with symptoms, and dried with forced air at $32^{\circ} \mathrm{C}$ to approximately $14 \%$ grain moisture. Grain was shelled from primary ears and bulked by experimental unit. Fifty kernels were sampled from each bulked experimental unit, disinfected for $60 \mathrm{~s}$ in $0.525 \% \mathrm{NaOCl}$ solution (Clorox Company, Oakland, CA), cultured on potato dextrose agar, and incubated at approximately $25^{\circ} \mathrm{C}$ for 5 days. Incidence of kernels infected was expressed as the percentage of kernels from which $F$. moniliforme, $F$. proliferatum, or $F$. subglutinans were isolated. The remaining bulked grain was ground with a Romer grinding-subsampling mill (model 2A; Romer Labs, Inc., Union, MO) to pass through a $1-\mathrm{mm}$ mesh. Ground grain was analyzed for the concentration of fumonisin with a competitive-direct enzymelinked immunosorbent assay (ELISA).

Multiwell microtiter plates were coated with protein-A (Sigma-Aldrich, St. Louis) and incubated overnight at $4^{\circ} \mathrm{C}$. Microtiter plates were washed (ELx405 Auto plate washer; Bio-Tek Instruments Inc., Winooski, VT) with $0.01 \mathrm{M}$ phosphate-buffered saline (PBS), and $100 \mu \mathrm{l}$ of rabbit sera polyclonal antibody (1:1000 dilution) was added to all wells. Plates were incubated at $27^{\circ} \mathrm{C}$ for $1 \mathrm{~h}$ before all wells were blocked with $1 \%$ polyvinyl alcohol (Sigma-Aldrich). Fumonisin was extracted by shaking a 25-g sample of ground corn from each experimental unit in $125 \mathrm{ml}$ of $0.1 \mathrm{M}$ PBS for $2 \mathrm{~h}$. After particulate material settled out of solution, a $100 \mu \mathrm{l}$ portion of extract from each sample was diluted (1:10) in $0.01 \mathrm{M}$ PBS amended with bovine serum albumin (Sigma-Aldrich) at $0.01 \mathrm{~g} / \mathrm{ml}$. A $100-\mu l$ portion of fumonisin standards, controls, or diluted sample extracts was added to mixing wells containing $100 \mu \mathrm{l}$ of fumonisin $\mathrm{B}_{1}$-horseradish peroxidase conjugate (1:2000 dilution; Chris Maragos, USDA-ARS). Solution $(100 \mu \mathrm{l})$ from each mixing well was transferred to the antibody-coated microtiter plates. Microtiter plates were incubated for $45 \mathrm{~min}$ at $27^{\circ} \mathrm{C}$ and washed with $0.01 \mathrm{M}$ PBS before $100 \mu \mathrm{l}$ of o-phenylenediamine citrate-phosphate buffer solution (SigmaAldrich) was added to all wells. Color development was stopped after $10 \mathrm{~min}$ by adding $100 \mu \mathrm{l}$ of $1 \mathrm{M} \mathrm{HCl}$ to all wells. Absorbance was measured at $490 \mathrm{~nm}$ with a Dynatech MR4000 absorbance meter (Dynatech Laboratories, Inc., Chantilly, VA). The concentration of fumonisin in grain samples was determined by comparing sample absorbance to a set of nine standards (range of 0 to $100 \mu \mathrm{g} / \mathrm{g}$ ) on each plate.

Concentration of fumonisin, severity of Fusarium ear rot, and incidence of kernels infected with Fusarium spp. were analyzed with analysis of variance via the Mixed procedure of Statistical Analysis System software (SAS institute, Cary, NC). Significant interaction terms were analyzed with single degree of freedom contrasts. Least squares means were sorted with the pdmix800 macro developed by Saxton (66). Concentration of fumonisin was transformed to the natural $\log$ to normalize residuals. Concentration of fumonisin and ear rot severity were analyzed in models in which data from years were combined, because there was no significant interaction between inoculation treatments and the years in which plants were grown. Incidence of kernels infected by Fusarium 
spp. was analyzed in models in which data from individual years were kept separate, because there was a significant interaction between inoculation treatments and the years in which plants were grown. Years and replicates were considered random terms in the appropriate models, and all other terms were considered fixed. Pearson's correlation coefficients were calculated between untransformed fumonisin concentration, ear rot severity, and incidence of kernels infected with Fusarium spp. Weather information for the Champaign-Urbana area was obtained from the Midwest Regional Climate Center, Champaign, IL.

\section{RESULTS}

Temperature and rainfall were higher than average in the summer of 1999. Growing degree days (dd; base 50) from June through September totaled 2,639 dd, with $43.4 \mathrm{~cm}$ of precipitation. Precipitation was generally greatest before pollination. The concentration of fumonisin in grain, severity of Fusarium ear rot, and incidence of kernels infected with Fusarium spp. for all experimental units ranged from nondetectable (n.d.) to $47 \mu \mathrm{g} / \mathrm{g}$ (mean $3 \mu \mathrm{g} / \mathrm{g}$ ), 0 to $61 \%$ (mean $5 \%$ ), and 4 to $100 \%$ (mean $89 \%$ ), respectively.

Temperature was near average and rainfall was lower than average in the summer of 2000. The period from June through September totaled 2,511 dd, with $32.0 \mathrm{~cm}$ of precipitation. Precipitation was generally greatest after pollination. The concentration of fumonisin in grain, severity of Fusarium ear rot, and incidence of kernels infected with Fusarium spp. for all experimental units ranged from n.d. to $244 \mu \mathrm{g} / \mathrm{g}$ (mean $12 \mu \mathrm{g} / \mathrm{g}$ ), 0 to $83 \%$ (mean $8 \%$ ), and 2 to $100 \%$ (mean $90 \%$ ), respectively.

Although the concentration of fumonisin was higher in 2000 than in $1999(P=$ $0.0005)$, rank order of treatments and hybrids did not differ among years. The yearinoculation treatment and year-hybrid interactions were not significant $(P=$ 0.1408 and $P=0.0737$, respectively). Fumonisin was affected significantly by the treatment-hybrid interaction $(P<0.0001)$. Severity of Fusarium ear rot was not affected significantly by year $(P=0.3701)$, or the year-treatment and year-hybrid interactions $(P=0.2034$ and 0.0525 respectively). Severity of Fusarium ear rot was affected significantly by the treatment-hybrid interaction $(P<0.0001)$. Incidence of kernels infected with Fusarium spp. differed among years $(P=$ $0.0169)$, and the year-treatment and yearhybrid interactions were significant $(P=$ 0.0131 and 0.0143 , respectively). Therefore, incidence of kernel infection was analyzed in models in which data from 1999 and 2000 were not combined.

Injection of a spore suspension through the ear husk $(P<0.0001$ in both years $)$, insertion of Fusarium-colonized toothpicks into the ear tip $(P=0.0033$ and 0.0165$)$, and the spray/cover/spray techniques $(P=$ 0.0033 and 0.0084 ) significantly increased the incidence of kernels infected with Fusarium spp. compared with a control in 1999 and 2000 (Fig. 1). The concentration of fumonisin $(P<0.0001)$ and severity of
Fusarium ear rot $(P=0.0055)$ were significantly greater than a control when plants were injected with a spore suspension through the ear husk (Fig. 1).

Hybrids inoculated by injection through the ear husk differed significantly for the concentration of fumonisin $(P=0.0008)$,

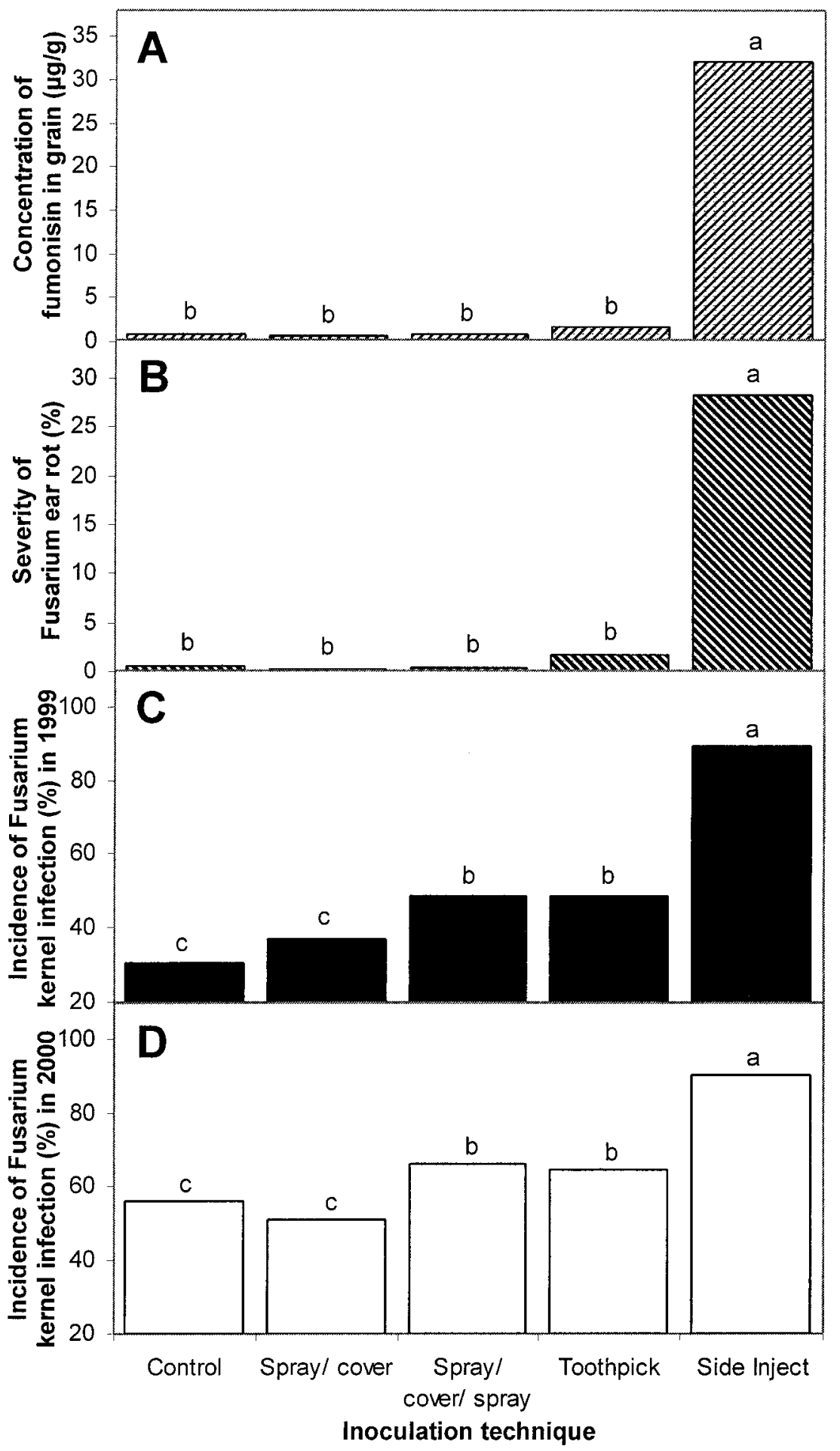

Fig. 1. A, Average concentration of fumonisin in grain, $\mathbf{B}$, severity of Fusarium ear rot, and $\mathbf{C}$ and $\mathbf{D}$, incidence of Fusarium kernel infection for four inoculation techniques and a control evaluated in 1999 and 2000 at Urbana, IL. Fumonisin and ear rot severity are presented untransformed as the average of treatment means over 2 years. Incidence of Fusarium kernel infection is presented as the average of treatment means per year. Treatments with unlike letters are significantly different $(\alpha=$ 0.05 ) as determined by differences between least squares means of natural log-transformed data for fumonisin and untransformed data for ear rot severity and incidence of Fusarium kernel infection. 
severity of Fusarium ear rot $(P=0.0179)$, and incidence of kernels infected with Fusarium spp. $(P=0.0244$ and 0.0005 in 1999 and 2000, respectively). Concentration of fumonisin was relatively low for
Monsanto hybrid DK635 (treatment mean $=1.9 \mu \mathrm{g} / \mathrm{g}$; Fig. 2). One hybrid, Pioneer Brand 34K77, had a concentration of fumonisin in grain that was not significantly different than DK635. Concentration of

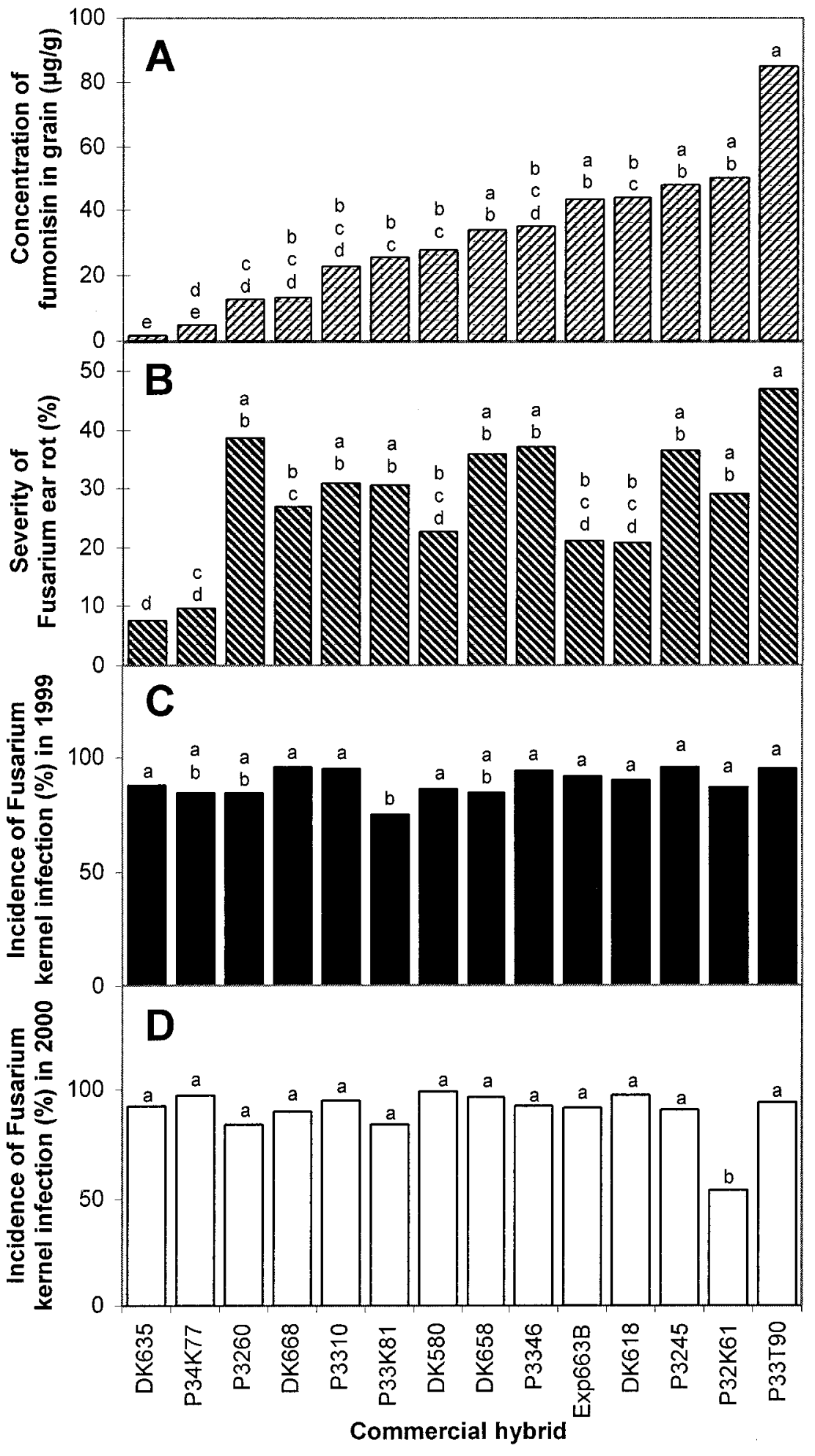

Fig. 2. A, Average concentration of fumonisin in grain, $\mathbf{B}$, severity of Fusarium ear rot, and $\mathbf{C}$ and $\mathbf{D}$, incidence of Fusarium kernel infection for 14 commercial corn hybrids evaluated by injection of inoculum through the ear husk in 1999 and 2000 at Urbana, IL. Fumonisin and ear rot severity are presented untransformed as the average of treatment means over 2 years. The incidence of Fusarium kernel infection is presented as the average of treatment means per year. Hybrids with unlike letters are significantly different $(\alpha=0.05)$ as determined by differences between least squares means of natural log-transformed data for fumonisin and untransformed data for ear rot severity and incidence of Fusarium kernel infection. fumonisin was highest for Pioneer Brand hybrid 33T90 (treatment mean $=84.8$ $\mu \mathrm{g} / \mathrm{g}$ ). Two Pioneer Brand hybrids (32K61 and 3245) and two Monsanto hybrids (Exp663B and DK658) had a concentration of fumonisin in grain that was not significantly different than 33T90.

Severity of Fusarium ear rot was relatively low for Monsanto hybrid DK635 (treatment mean $=7.7 \%$; Fig. 2 ). Three Monsanto hybrids (DK580, Exp663B, and DK618) and one Pioneer Brand hybrid (34K77) had severity of ear rot that was not significantly different than DK635. Severity of Fusarium ear rot was highest for Pioneer Brand hybrid 33T90 (treatment mean $=47 \%$ ). Six Pioneer Brand hybrids (32K61, 3260, 3245, 3346, 33K81, and 3310) and one Monsanto hybrid (DK658) had severity of ear rot that was not significantly different than 33T90.

Incidence of kernels infected with Fusarium spp. was lowest for Pioneer Brand hybrids 33K81 (treatment mean = $75 \%)$ and $32 \mathrm{~K} 61$ (treatment mean $=54 \%$ ) in 1999 and 2000, respectively (Fig. 2). Two Pioneer Brand hybrids (34K77 and 3260) and one Monsanto hybrid (DK658) had incidence of kernel infection that was not significantly different than the numerically lowest incidence of infection in 1999 only.

Pearson's correlation coefficient for ear rot severity and fumonisin in grain of hybrids injected with a spore suspension through the ear husk was $r=0.73(P<$ 0.0001; Fig. 3). The incidence of kernels infected with Fusarium spp. for hybrids injected with a spore suspension through the ear husk was not correlated with ear rot severity in $1999(P=0.9445)$ or $2000(P=$ $0.8898)$, or with the concentration of fumonisin in $1999(P=0.6488)$ or $2000(P=$ 0.7549).

\section{DISCUSSION}

A highly efficient inoculation technique was identified that consistently differentiated hybrids for concentration of fumonisin and severity of Fusarium ear rot over 2 years. A spore suspension is injected beneath the ear husk leaves at approximately 1 week after pollination; thereby placing inoculum into direct contact with a large number of corn kernels. Contact between corn kernels and Fusarium spp. during an early stage in kernel development may favor infection and promote establishment of the pathogen. Although very few kernels (typically 0 to 2) are wounded by this technique, the small amount of damage that does occur may aide in pathogen establishment beneath the husk leaves. Once established beneath the husk leaves, $F$. verticillioides and $F$. proliferatum should be less subject to the influence of external environmental conditions. Kernel traits associated with pathogen growth and fumonisin production (e.g., pericarp development $[36,69]$ or synthesis of distinct 
proteins) may be selected as a result of this method of inoculation.

Concentration of fumonisin and severity of ear rot were positively correlated when hybrids were injected with a spore suspension through the ear husk. Although this relationship describes a general trend, several hybrids were identified with low to moderate ear rot severity and a concentration of fumonisin in grain at levels of concern. This is similar to previous research which identified fumonisins at levels of concern in asymptomatic corn kernels destined for human consumption $(12,60)$. These results underscore the need to select against both ear rot and fumonisin in grain.

In our study, incidence of kernels infected with Fusarium spp. was high and not an effective indicator of ear rot severity or fumonisin in grain (Fig. 2). This is comparable to the observation made by Drepper et al. (19), where incidence of kernels infected with Fusarium spp. differed little among inoculation techniques for Fusarium ear rot. Further, kernel infection was affected by the interaction of hybrids with years, and was therefore not a dependable means of differentiating hybrids as resistant or susceptible to infection (Fig. 2). The concentration of fumonisin in grain and severity of Fusarium ear rot were not affected by the interaction of hybrids with years, and therefore were useful for differentiating resistant and susceptible hybrids. Factors affecting kernel infection may operate independently from those affecting fumonisin production, and the continued symptomatic or asymptomatic growth of $F$. verticillioides and $F$. proliferatum within and on the ear. Natural infection by endemic Fusarium fungi, as suggested by the high incidence of kernel infection on ears that were not inoculated with Fusarium spp. also may have confounded relationships between kernel infection and fumonisin production, or kernel infection and severity of Fusarium ear rot. High incidence of kernel infection by Fusarium spp. on naturally infected grain in Illinois (40), Missouri (6), Mississippi (39), and other areas has been reported.

With few exceptions in the literature, general conclusions can be made about successful inoculation techniques for Fusarium ear rot. Techniques that do not damage plant tissues tend to be most effective when scheduled within the first few weeks following pollination (67), whereas techniques that damage plant tissues are less dependent upon the time of inoculation for their success (67). Techniques that apply inoculum to kernels or silks appear to contribute to kernel infection more effectively than techniques that emphasize systemic movement of Fusarium spp. from other plant tissues to kernels $(46,50)$. Techniques that wound the ear tissues or insert inoculum beneath the husk leaves result in more severe ear rot than techniques that apply inoculum to exterior plant surfaces without wounding $(3,5,19,67)$.

Two techniques, toothpicks and injection, capitalize on all of these characteristics by placing inoculum into direct contact with corn kernels or silks at an early stage of ear development. Both techniques damage a very small number of kernels at the inoculation site; however, all of the kernels surrounding the toothpick inoculation site are at the extreme tip of the ear, and most abort early in ear development. Failure of the toothpick technique may be due to the lack of living tissue surrounding the inoculation site, but is most likely due to the low level of inoculum delivered to the ear. The injection technique places a large volume of inoculum beneath the husk leaves into a high-nutrient, high-moisture region of wounded and nonwounded tissue. Direct and early contact between the pathogen and living kernels may promote severe ear rot and a high concentration of fumonisin in grain of susceptible genotypes.

Traits such as tight husk leaves $(2,20,34,40,58,78)$ and prolonged silk survival (32-34) appear to contribute to resistance of some genotypes by imposing a barrier between kernels and inoculum sources. Various insects have been implicated as vectors of $F$. verticillioides in corn $(11,15,17,18,20,26,28,40,42,43,48,49,59,62$, $71,72,81)$; therefore, the effectiveness of these types of resistance may be reduced in environments where Fusarium spp. gain access to kernels through damage caused by insects. Injection of a spore suspension through the husk leaves bypasses silk and husk tissue. Consequently, genotypes that rely on tight husk leaves or prolonged silk survival for resistance may be overlooked in trials inoculated by injection. Our injection technique places inoculum into direct contact with wounded and nonwounded corn kernels at an early stage of ear development, and should identify lines that provide reliable suppression of fumonisin and Fusarium ear rot when disease development is favored.

The ELISA to quantify fumonisin in this study was adapted from a technique first developed at the USDA-ARS-NCAUR (Peoria, IL) and the Immunological Resource Center at the University of Illinois (Urbana). The ELISA is based on a rabbit polyclonal antibody and will detect $\geq 1 \mu \mathrm{g}$ of the intact fumonisins $\mathrm{B}_{1}, \mathrm{~B}_{2}$, and $\mathrm{B}_{3}$ per gram of ground corn (equivalent to $20 \mathrm{ng} / \mathrm{g}$ in the diluted test solution). The procedure will not detect hydrolyzed fumonisins. Greater sensitivity from the polyclonal antibody $(\geq 0.02 \mu \mathrm{g} / \mathrm{g}$ ) is possible in phosphate buffer in the absence of a corn matrix. Cross reactivity of the antibody with fumonisin precursors or other metabolites is unknown. The ELISA is an acceptable method for determining relative differences in the concentration of fumonisin between grain samples. This assay compared favorably with high-performance liquid chromatography (HPLC) when 59 ground corn samples were examined in 2001. Of 11 samples identified with HPLC with fumonisin at $\leq 7 \mu \mathrm{g} / \mathrm{g}$ of ground corn, 10 were identified with ELISA. The concentration of fumonisin in the eleventh sample was determined to be $8 \mu \mathrm{g} / \mathrm{g}$ with ELISA (M. J. Clements, R. D. Plattner, M. E. Tumbleson, and D. G. White, unpublished).

The injection technique identified in this study is suitable for the efficient evaluation of a large number of corn genotypes for resistance to Fusarium ear rot and fumonisin. Hybrids and inbreds have been evaluated successfully with this technique for resistance to fumonisin and Fusarium ear rot. This technique is being used in projects to assess potential fumonisin contamination of commercially available foodgrade hybrids, to identify inbred lines with resistance to fumonisin and Fusarium ear rot, and to identify quantitative trait loci associated with resistance to fumonisin and Fusarium ear rot.

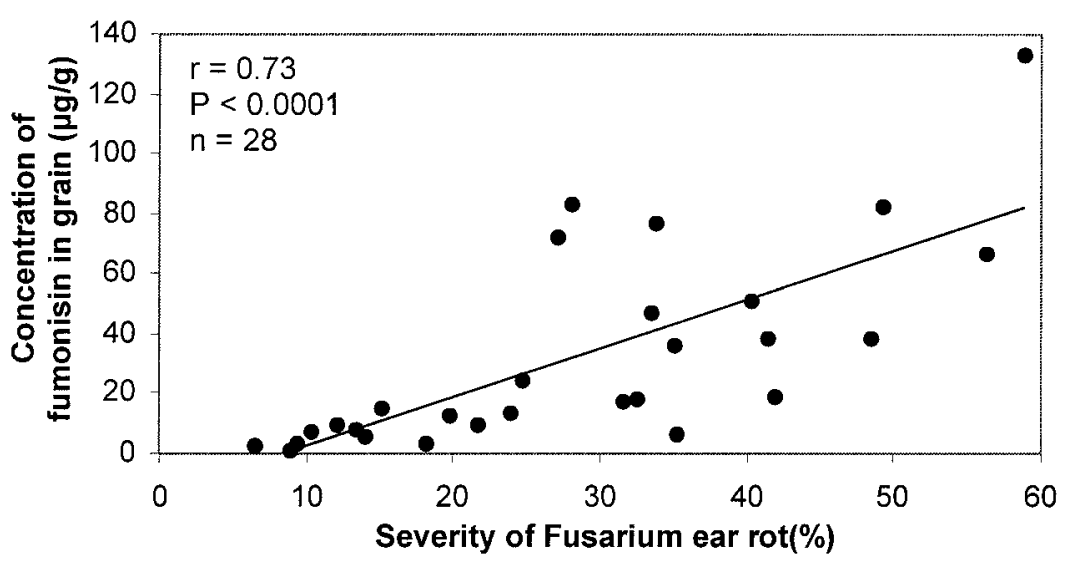

Fig. 3. Scatter diagram for severity of Fusarium ear rot and the concentration of fumonisin in grain of 14 commercial corn hybrids evaluated by injection of a spore suspension through the ear husk in 1999 and 2000 at Urbana, IL. Individual data points represent the average of four replicates per year. Line through points is a linear regression. 


\section{ACKNOWLEDGMENTS}

We thank Pioneer Hi-bred International, Inc. and Monsanto Company for providing the hybrid seed that made this experiment possible; C. A. Smyth for assistance with statistical analysis of this data; and D. E. Severns, S. K. Sipp, R. D. Plattner, M. E. Tumbleson, and A. E. Desjardins for assistance provided during lab and field work.

\section{LITERATURE CITED}

1. Anderson, B. M., and Dolezal, W. E. 1993. Prevalence and distribution of fumonisin in the United States. 48th Annu. Corn Sorghum Res. Conf. Chicago.

2. Boewe, G. H. 1936. The relation of ear rot prevalence in Illinois corn fields to ear coverage by husks. IL. Nat. Hist. Survey Biol. Notes No. 6. Urbana, IL

3. Boling, M., Grogan, C., and Broyles, J. 1963. A new method for artificially producing epiphytotics of Fusarium ear rot of maize. Plant Dis. Rep. 47:315-317.

4. Bullerman, L. B., and Tsai, W. J. 1994. Incidence and levels of Fusarium moniliforme, Fusarium proliferatum and fumonisins in corn and corn-based foods and feeds. J. Food Prot. 57:541-546.

5. Bush, B. J. 2001. Fusarium verticillioides infection, fumonisin contamination and resistance evaluation in North Carolina maize. M.S. thesis. Department of Plant Pathology, North Carolina State University, Raleigh.

6. Calvert, O. H., Foudin, A. S., Minor, H. C., and Krause, G. F. 1985. Fusarium moniliforme colonization of corn ears in Missouri. Plant Dis. 69(11):988-990.

7. Castelo, M. M., Sumner, S., and Bullerman, L. B. 1998. Occurrence of fumonisins in cornbased food products. J. Food Prot. 61:704707.

8. Center for Food Safety and Applied Nutrition. 2001. Background paper in support of fumonisin levels in corn and corn products intended for human consumption. On line. USFDA Center for Food Safety and Applied Nutrition. Last updated 9 November 2001.

9. Center for Food Safety and Applied Nutrition. 2001. Guidance for Industry: Fumonisin levels in human foods and animal feeds. On line. USFDA Center for Food Safety and Applied Nutrition and the Center for Veterinary Medicine. Last updated 9 November 2001

10. Cheng, S. J., Jiang, Y. Z., Li, M. H., and Lo, H. Z. 1985. A mutagenic metabolite produced by Fusarium moniliforme isolated from Linxian County, China. Carcenogenesis 6:903-905.

11. Christensen, J. J., and Schneider, C. L. 1950. European corn borer (Pyrausta nubilalis HBN.) in relation to shank, stalk, and ear rots of corn. Phytopathology 40:284-291.

12. Chu, F. S., and Li, G. Y. 1994. Simultaneous occurrence of fumonisin B1 and other mycotoxins in moldy corn collected from the People's Republic of China in regions of high incidences of esophageal cancer. Appl. Environ. Microbiol. 60:847-852.

13. Clements, M. J. 2002. Resistance to fumonisins and Fusarium ear rot of corn. Ph.D. thesis. Department of Crop Sciences, University of Illinois, Urbana.

14. Colvin, B. M., and Harrison, L. R. 1992. Fumonisin-induced pulmonary edema and hydrothorax in swine. Mycopathologia 117:79-82.

15. Davis, R. M., Kegel, F. R., Sills, W. M., and Farrar, J. J. 1989. Fusarium ear rot of corn. Calif. Agric. 43(6):4-5.

16. Doko, M. B., and Visconti, A. 1994. Occurrence of fumonisins $\mathrm{B} 1$ and $\mathrm{B} 2$ in corn and corn-based human foodstuff in Italy. Food Addit. Contam. 11:433-439.

17. Dowd, P. F. 2000. Indirect reduction of ear molds and associated mycotoxins in Bacillus thuringiensis corn under controlled and open field conditions: utility and limitations. J. Econ. Entomol. 93(6):1669-1679.

18. Dowd, P. F. 2001. Biotic and abiotic factors limiting efficacy of $\mathrm{Bt}$ corn in indirectly reducing mycotoxin levels in commercial fields. J. Econ. Entomol. 94(5):1067-1074

19. Drepper, W. J., and Renfro, B. L. 1990. Comparison of methods for inoculation of ears and stalks of maize with Fusarium moniliforme. Plant Dis. 74:952-956.

20. Farrar, J. J., and Davis, R. M. 1991. Relationships among ear morphology, western flower thrips, and Fusarium ear rot of corn. Phytopathology 81:661-666.

21. Fincham, J. E., Marasas, W. F. O., Taljaard, J. J. F., Kreik, N. P. J., Badenhorst, C. J., Gelberblom, W. C. A., Seier, J. V., Smuts, C. M., Faber, M., Weight, M. J., Slazus, W., Woodroof, C. W., VanWyk, M. J., Kruger, M., and Thiel, P. G. 1992. Atherogenic effects in a nonhuman primate of Fusarium moniliforme cultures added to a carbohydrate diet. Atherosclerosis $94: 13-25$.

22. Gelderblom, W. C. A., Cawood, M. E., Snyman, S. D., Vleggaar, R., and Marasas, W. F. O. 1993. Structure-activity relationships of fumonisins in short-term carcenogenesis and cytotoxicity assays. Food Chem. Toxicol. 31:407-414.

23. Gelderblom, W. C. A., Jaskiewicz, K., Marasas, W. F. O., Thiel, P. G., Horak, R. M., Vleggaar, R., and Kriek, N. P. J. 1988. Fumonisins: Novel mycotoxins with cancer-promoting activity produced by Fusarium moniliforme. Appl. Environ. Microbiol. 54:1806-1811.

24. Gelderblom, W. C. A., Kreik, N. P. J., Marasas, W. F. O., and Thiel, P. G. 1991. Toxicity and carcenogenicity of the Fusarium moniliforme metabolite, fumonisin $\mathrm{B} 1$, in rats. Carcenogenesis 12:1247-1251.

25. Gelineau-vanWaes, J., Maddox, J., Grabowski, L., Heller, S., and Bennett, G. 2001. Role of folate in fumonisin B1-Induced neural tube defects. 1st Fungal Genomics, 2nd Fumonisin Elimination and 14th Aflatoxin Elimination Workshops, Phoenix, AZ.

26. Gould, F. 1998. Sustainability of transgenic insecticidal cultivars: Integrating pest genetics and ecology. Annu. Rev. Entomol. 43:701-26.

27. Gulya, T. J., Martinson, C. A., and Loesch, P. J. 1980. Evaluation of inoculation techniques and rating dates for Fusarium ear rot of opaque-2 maize. Phytopathology 70:11161118

28. Hammond, R., Campbell, K., Pilcher, C., Degooyer, T., Robinson, A., Rice, L., Pietri, A., Piva, G., Melcion, D., and Cahagnier, B. 2001. Reduction of fungal and fumonisin levels in Bt corn. 1st Fungal Genomics, 2nd Fumonisin Elimination and 14th Aflatoxin Elimination Workshops, Phoenix, AZ.

29. Harrison, L. R., Colvin, B. M., Greene, J. T., Newman, L. E., and Cole, J. R. 1990. Pulmonary edema and hydrothorax in swine produced by fumonisin B1, a toxic metabolite of Fusarium moniliforme. J. Vet. Diagnostic Investigation 2:217-221.

30. Haschek, W. M., Motelin, G., Ness, D. K., Harlin, K. S., Hall, W. F., Vesonder, R. F., Peterson, R. E., and Beasley, V. R. 1992. Characterization of fumonisin toxicity in orally and intravenously dosed swine. Mycopathologia 117:83-96

31. Headrick, J. M., and Pataky, J. K. 1989. Resistance to kernel infection by Fusarium moniliforme in inbred lines of sweet corn and the effect of infection on emergence. Plant Dis. 73:887-892.

32. Headrick, J. M., and Pataky, J. K. 1991. Maternal influence on the resistance of sweet corn lines to kernel infection by Fusarium moniliforme. Phytopathology 81:268-274.

33. Headrick, J. M., Pataky, J. K., and Juvick, J. A. 1990. Relationships among carbohydrate content of kernels, condition of silks after pollination, and the response of sweet corn inbred lines to infection by Fusarium moniliforme. Phytopathology 80:487-494.

34. Hesseltine, C. W., and Bothast, R. J. 1977. Mold development in ears of corn from tasseling to harvest. Mycologia 69:328-340.

35. Hlywka, J. J., and Bullerman, L. B. 1999. Occurrence of fumonisin B1 and B2 in beer. Food Addit. Contam. 16(8):319-324.

36. Hoenisch, R. W., and Davis, R. M. 1994 Relationship between kernel pericarp thickness and susceptibility to Fusarium ear rot in field corn. Plant Dis. 78:517-519.

37. Hopmans, E. C., and Murphy, P. A. 1993. Detection of fumonisins B1, B2 and B3 and hydrolyzed fumonisin B1 in corn-containing foods. J. Agric. Food Chem. 41:1655-1658.

38. Kellerman, T. S., Marasas, W. F. O., Thiel, P G., Gelberblom, W. C. A., Cawood, M., and Coetzer, J. A. W. 1990. Leukoencephalomalacia in two horses induced by oral dosing of fumonisin B1. Onderstepoort J. Vet. Res. 57:269-275.

39. King, S. B., and Scott, G. E. 1981. Genotypic differences in maize to kernel infection by Fusarium moniliforme. Phytopathology 71(12):1245-1247

40. Koehler, B. 1942. Natural mode of entrance of fungi into corn ears and some symptoms that indicate infection. J. Agric. Res. 64:421-442.

41. Kreik, N. N. J., Kellerman, T. S., and Marasas, W. F. O. 1981. A comparative study of the toxicity of Fusarium verticillioides $(=F$. moniliforme) to horses, primates, pigs, sheep, and rats. Onderstepoort J. Vet. Res. 48:129131.

42. Lynch, R. E., Wiseman, B. R., Plaisted, D., and Warnick, D. 1999. Evaluation of transgenic sweet corn hybrids expressing Cry1A(b) toxin for resistance to corn earworm and fall armyworm (Lepidoptera: Noctuidae). J. Econ. Entomol. 92:246-252.

43. Lynch, R. E., Wiseman, B. R., Sumner, H. R. Plaisted, D., and Warnick, D. 1999. Management of corn earworm and fall armyworm (Lepidoptera: Noctuidae) injury on a sweet corn hybrid expressing a cry1A(b) gene. J. Econ. Entomol. 92(5):1217-1222.

44. Marasas, W. F. O., Kellerman, T. S., Gelberblom, W. C. A., Coetzer, J. A. W., and Thiel, P. G. 1988. Leukoencephalomalacia in a horse induced by fumonisin B1 isolated from Fusa rium moniliforme. Onderstepoort $\mathrm{J}$. Vet. Res. 55:197-203.

45. Miller, M. A., Honstead, J. P., and Lovell, R. A. 1996. Regulatory aspects of fumonisin with respect to animal feeds. In: Fumonisins in Food. L. Jackson, J. DeVries, and L. Bullerman, ed. Plenum Press, New York.

46. Munkvold, G. P., and Carlton, W. M. 1997. Influence of inoculation method on systemic Fusarium moniliforme infection of maize plants grown from infected seeds. Plant Dis. 81(2):211-216

47. Munkvold, G. P., and Desjardins, A. E. 1997. Fumonisins in maize, can we reduce their occurrence? Plant Dis. 81:556-565.

48. Munkvold, G. P., Hellmich, R. L., and Rice, L. G. 1999. Comparison of fumonisin concentration in kernels of transgenic Bt maize hybrids and nontransgenic hybrids. Plant Dis. 83:130-138.

49. Munkvold, G. P., Hellmich, R. L., and Showers, W. B. 1997. Reduced Fusarium ear rot and symptomless infection in kernels of maize genetically engineered for European corn borer resistance. Phytopathology 87(10):1071-1077 
50. Munkvold, G. P., McGee, D. C., and Carlton, W. M. 1997. Importance of different pathways for maize kernel infection by Fusarium moniliforme. Phytopathology 87:209-217.

51. Murphy, P. A., Rice, L. G., and Ross, P. F. 1993. Fumonisin B1, B2 and B3 content of Iowa, Wisconsin and Illinois corn and corn screenings. J. Agric. Food Chem. 41:263-268.

52. Musser, S. M., and Plattner, R. D. 1997. Fumonisin composition in cultures of Fusarium moniliforme, Fusarium proliferatum, and Fusarium nygami. J. Agric. Food Chem. 45:1169-1173.

53. Nelson, P. E. 1992. Taxonomy and biology of Fusarium moniliforme. Mycopathologia 117:29-36

54. Nelson, P. E., Desjardins, A. E., and Plattner, R. D. 1993. Fumonisins, mycotoxins produced by Fusarium species: Biology, chemistry, and significance. Annu. Rev. Phytopathol. 31:233-252.

55. National Toxicology Program. 1999. Toxicology and carcinogenesis studies of fumonisin $\mathrm{B} 1$ in $\mathrm{F} 344 / \mathrm{N}$ rats and $\mathrm{B} 6 \mathrm{C} 3 \mathrm{~F} 1$ mice (feed studies). Tech. Rep. NTP Central Data Management, U. S. Dep. Health Human Serv. Public Health Service, National Institutes of Health. TR-496. CAS No 116355-83-0. Research Triangle Park, NC.

56. Osweiler, G. D., Ross, P. F., Wilson, T. M., Nelson, P. E., Witte, S. T., Carson, T. L., Rice, L. G., and Nelson, H. A. 1992. Characterization of an epizootic of pulmonary edema in swine associated with fumonisin in corn screenings. J. Vet. Diagn. Invest. 4:53-59.

57. Pestka, J. J., Azcona-Olivera, J. I., Plattner, R. D., Minervini, F., Doko, M. B., and Visconti, A. 1994. Comparative assessment of fumonisin in grain-based foods by ELISA, GCMS, and HPLC. J. Food Prot. 57:169-172.

58. Phillips, W. J., and Barber, G. W. 1931. The value of husk protection to corn ears in limiting corn earworm injury. Va. Agric. Exp. Stn. Bull. No. 43

59. Pilcher, C. D., Rice, M. E., Obrycki, J. J., and Lewis, L. C. 1997. Field and laboratory evaluations of transgenic Bacillus thuringiensis corn on secondary Lepidopteran pests (Lepidoptera: Noctuidae). J. Econ. Entomol. 90:669-678.

60. Rheeder, J. P., Marasas, W. F. O., Thiel, P. G., Sydenham, E. W., Shephard, G. S., and Schalkwyk, D. J. V. 1992. Fusarium moniliforme and fumonisins in corn in relation to human esophageal cancer in Transkei. Phytopathology 82:353-357.

61. Rice, L. G., and Ross, P. F. 1994. Methods for detection and quantitation of fumonisins in corn cereal products and animal excreta. J. Food Prot. 57(6):536-540.

62. Rice, M. E., and Pilcher, C. D. 1998. Potential benefits and limitations of transgenic Bt corn for management of the European corn borer (Lepidoptera: Crambidae). Am. Entomol. 44:75-77.

63. Ross, P. F. Ledet, A. E. Owens, D. L., Rice, L. G., Nelson, H. A., Osweiler, G. D., and Wilson, T. M. 1993. Experimental equine leukoencephalomalacia, toxic hepatosis, and encephalopathy caused by corn naturally contaminated with fumonisins. J. Vet. Diagn. Invest. 5:69-74.

64. Ross, P. F., Nelson, P. E., Richard, J. L., Osweiler, G. D., Rice, L. G., Plattner, R. D., and Wilson, T. M. 1990. Production of fumonisins by Fusarium moniliforme and Fusarium proliferatum isolates associated with equine leukoencephalomalacia and a pulmonary edema syndrome in swine. Appl. Environ. Microbiol. 56(10):3225-3226

65. Salazar, F., and Vargas, E. 1977. Methods of evaluation and levels of resistance in maize to the rotting of ears caused by Fusarium moniliforme. Agron. Costarric. 1:93-99.

66. Saxton, A. M. 1988. A macro for converting mean separation output to letter groupings in Proc Mixed. 23rd SAS Users Group Int. Nashville, TN.

67. Schaafsma, A. W., Miller, J. D., Savard, M. E., and Ewing, R. J. 1993. Ear rot development and mycotoxin production in corn in relation to inoculation method, corn hybrid, and species of Fusarium. Canadian J. Plant Pathol. 15:185-192.

68. Scott, D. H., Grogan, J., Gann, R., Everson, R. J., and Binkerd, K. 1992. Summary of 1989, 1990, and 1991 pre-harvest corn ear rot/ mycotoxin survey in Indiana. Purdue Univ. Agric. Exp. Stn. Bull. 645. West Lafayette, IN.

69. Scott, G. E., and King, S. B. 1984. Site of action of factors for resistance to Fusarium moniliforme in maize. Plant Dis. 68:804-806.

70. Shelby, R. A., White, D. G., and Bauske, E. M. 1994. Differential fumonisin production in maize hybrids. Plant Dis. 78:582-584.

71. Smeltzer, D. G. 1959. Relationship between Fusarium ear rot and corn earworm infesta- tion. Agron. J. 51:53-54.

72. Sobek, E. A., and Munkvold, G. P. 1999 European corn borer (Lepidoptera: Pyralidae) larvae as vectors of Fusarium moniliforme, causing kernel rot and symptomless infection of maize kernels. J. Econ. Entomol. 92(3):503-509.

73. Stack, M. E. 1998. Analysis of fumonisin B1 and its hydrolysis product in tortillas. $\mathrm{J}$. AOAC Int. 81:737-740.

74. Stack, M. E., and Eppley, R. M. 1992. Liquid chromatographic determination of fumonisins $\mathrm{B} 1$ and $\mathrm{B} 2$ in corn and corn products. $\mathrm{J}$ AOAC Int. 75(5):834-837.

75. Sydenham, E. W., Shephard, G. S., Thiel, P. G., Marasas, W. F. O., and Stokenstrom, S 1991. Fumonisin contamination of commercial corn based human foodstuffs. J. Agric. Food Chem. 39:2014-2018.

76. Sydenham, E. W., Thiel, P. G., Marasas, W. F O., Shephard, G. S., Schalkwyk, D. J. V., and Koch, K. R. 1990. Natural occurrence of some Fusarium mycotoxins in corn from low and high esophageal cancer prevalence areas of the Transkei, South Africa. J. Agric. Food Chem. 38:1900-1903.

77. Thiel, P. G., Marasas, W. F. O., Sydenham, E. W., Shephard, G. S., and Gelderblom, W. C. A. 1992. The implications of naturally occurring levels of fumonisins in corn for human and animal health. Mycopathologia 117:3-9.

78. Warfield, C. Y., and Davis, R. M. 1996. Importance of the husk covering on the susceptibility of corn hybrids to Fusarium ear rot. Plant Dis. 80(2):208-210.

79. White, D. G., ed. 1999. Compendium of Corn Diseases, 3rd ed. American Phytopathological Society Press, St. Paul, MN.

80. Wilson, T. M., Ross, P. F., Owens, D. L., Rice, L. G., Green, S. A., Jenkins, S. J., and Nelson, H. A. 1992. Experimental reproduction of ELEM - a study to determine the minimum toxic dose in ponies. Mycopathologia 117:115-120.

81. Windels, C. E., Windels, M. B., and Kommedahl, T. 1976. Association of Fusarium species with picnic beetles on corn ears. Phytopathology 66:328-331.

82. Woloshuk, C. P., Gann, R., and Everson, R. J. 2001. Fusarium ear rot and fumonisin contamination: An Indiana survey 1991-2001. 1st Fungal Genomics, 2nd Fumonisin Elimination and 14th Aflatoxin Elimination Workshops, Phoenix, AZ. 